\title{
Risk-taking and Performance of Small and Medium-sized Enterprises: Lessons from Tanzanian Bakeries
}

\author{
Kafigi Jeje \\ College of Law and Management Studies, University of KwaZulu-Natal, South Africa \\ 217050911@stu.ukzn.ac.za
}

\begin{abstract}
SMEs are the major drivers of socioeconomic development of many economies. In order to influence economic growth, SMEs must be capable of enhancing their competiveness, growth, and sustainability. These capabilities are acquired by SMEs that understand and adopt entrepreneurial strategies that work. There is abundant literature confirming that one of these entrepreneurial strategies include risktaking practices. SMEs are still facing challenges to understand and apply the right risk-taking strategies that influence their performance. We therefore characterize risk-taking as risk planning, risk controlling, and strategic risk initiatives, and seek to establish their contribution on SME performance. This study draws lessons from the risk management practices of small and medium-sized bakeries in Tanzania where agriculture, a sector that directly relates with bakery business, is one of the leading sectors in driving economic growth. We adopt a multi-stage sampling technique and receive responses from 161 questionnaires, and 20 in depth interviews from bakery owners/managers throughout Tanzania. The principal component analysis, qualitative content analysis (manifest analysis), and the moderator analysis are used in analyzing these data. We ascertain that both the firm age, and the gender of the owner/manager moderate the relationship between risk-taking strategies and SME performance. We argue that SMEs have the responsibilities of improving their risk-taking practices and capabilities in order to drive their competitiveness. Additionally, SMEs need to employ their efforts and resources in supporting their risk management initiatives, and integrate them in their business operations, and policy development practices, and ultimately advance their sustainability.
\end{abstract}

Keywords: Risk planning, risk controlling, strategic risk initiatives, SME performance, Tanzanian bakeries.

\section{Introduction}

The contribution of SMEs on the world economy is enormous. Their growth impacts both developed and developing economies. SMEs account for almost 99\% of all enterprises around the globe (Robu, 2013; Savlovschi \& Robu, 2011). In Sub-Saharan Africa, they account for 95\% of all operating businesses (Fjose, Grünfeld, \& Green, 2010). In this regard, their contribution on socio-economic developement and poverty reduction is undisputable (Katua, 2014; Savlovschi \& Robu, 2011). Tanzania has always enjoyed the presence of SMEs in its economy. Their contribution in GDP growth, poverty reduction (URT, 2012), and in creating employment opportunities (Maliti \& Mnenwa, 2008) is significant. Despite their contribution to Tanzania's socio-economic development, Tanzanian SMEs have been facing a lot of challenges. Failure to meet the growing demands and customer needs, failure to understand the customers and markets, poor networking strategies (Kazimoto, 2014), poor information management skills (Richard \& Mori, 2012), poor access to finance (Mashenene \& Rumanyika, 2014; Kazimoto, 2014; Richard \& Mori, 2012), poor entrepreneurship training, lack of entrepreneurial culture (Mashenene \& Rumanyika, 2014), engagement in unstable networks (Kazimoto, 2014), and failure to execute developed strategic plans (Mori, Kazungu, \& Mchopa, 2014) are a few examples of the challenges. Most of these challenges can be addressed if Tanzanian SMEs are capable of accessing business information, and creating sound strategies that enable them to analyze the needs of their customers, and be able to access markets, and finance. However, these capabilities can be enhanced by relevant and frequent business training (Kazimoto, 2014). Tanzanian SMEs need proper business knowledge and skills that promote their entrepreneurial competency (Mashenene \& Rumanyika, 2014). Additionally, in order to address most of the challenges, the employees in Tanzanian SMEs should be given autonomy in managing business operations (Kapaya, Shayo, Jaensson, \& Stanslaus, 2018). Tanzanian SMEs can enhance their business operations if they get an opportunity to exchange useful business information with key players (Hamisi, 2011). The acquired business information can be used in addressing most of their growth barriers (Kazimoto, 2014). Conversely, Tanzanian SMEs are reluctant in sharing information to key players due to the fact that the information are likely to be acquired by their major rivals, and ultimately pose potential risks to their business interests and goals (Katunzi \& Zheng, 2010). However, there are a lot of benefits gained when 
SMEs share resources and information (Bengesi \& Le Roux, 2014). Collaborations are likely to enable Tanzanian SMEs access markets, attain efficiency through reduced transaction costs (Nyangarika, 2016).

The growth of SMEs is heavily dependent on their capabilities and readiness to initiate and implement changes, particularly the adoption of entrepreneurial strategies that work. One of these strategies is risktaking. SMEs need to manage risks in order to influence their profitability (Nanthuru, Pingfeng, Guihua, \& Mkonya, 2018). Risk-taking can be defined as the propensity that involves bold engagements in product development, technological innovations, venturing into the unknown, embracing considerable borrowing, and injecting a great amount of resources in uncertain environments in order to meet current and future demand, increase profitability, and for the sake of outperforming rivals (Mason, Floreani, Miani, Beltrame, \& Cappelletto, 2015; Lawal, Adegbuyi, Iyiola, Ayoade, \& Taiwo, 2018; Kitigin, 2017). Risks are found in both internal and external business environments. These environments contribute significantly to SME performance (Basile, 2012). For example, the internal environments may result to risks that are associated with the incompetency of staff, poor accessibility of resources, bankruptcy of key business stakeholders and partners, failure to manage contracts, and weak compliance of relevant rules, regulations, and standards. On the other hand, risks from the external environments may be linked with economic situations, dynamics in politics, purchasing power, legal, and tax systems (Belinskaja \& Velickiene, 2015). Risk-taking can drive SME competitiveness (Lawal, Adegbuyi, Iyiola, Ayoade, \& Taiwo, 2018; Kitigin, 2017; Bakar \& Zainol, 2015). For example, risk management knowledge can drive financial performance (Nanthuru, Pingfeng, Guihua, \& Mkonya, 2018). However, the risk management capabilities of most SMEs are very low. For example, most of the SMEs lack know-how in managing business operations, and in making financial and marketing forecasts (Smit \& Watkins, 2012) despite the fact that their readiness to take risks is very high (Dominguez \& Raïs, 2012).

Most of the SMEs face difficulties when it comes to intertwining risk practices and business processes (Gorzeń-Mitka, 2015). In this regard, SMEs are likely to increase their costs if they fail to manage risks (Nanthuru, Pingfeng, Guihua, \& Mkonya, 2018). Therefore, risk management techniques that suit the need of SMEs should be in place (Kagwathi, Kamau, Njau, \& Kamau, 2014). These techniques require the capabilities of SME owners/managers in foretelling potential hazards (Smit \& Watkins, 2012). The SMEs are also required to adopt relevant instruments that can manage risks associated with the business operations in relation to the respective internal and external business environments. These instruments should be the drivers of SME performance (Belinskaja \& Velickiene, 2015). For example, tools such as enterprise risk management can be adopted in order to manage risks, costs, and ultimately integrate risk practices in their strategic objectives. These tools enable SMEs to assess their risk management strategies and capabilities, and to prioritize risks according to needs and resources (Smit \& Watkins, 2012). However, SMEs need to enhance their learning environments, research capabilities, and utilize knowledge in business practices, and increase their entrepreneurial spirit (Zhai, Sun, Tsai, Wang, Zhao, \& Chen, 2018). Therefore, the SMEs' risk management practices are likely to influence their competitiveness if employees are involved in the risk management processes that involve risk planning, risk controlling, and risk evaluation (Smit \& Watkins, 2012). The risk management processes need to be integrated in the SME's business operations, processes, practices, strategies, objectives, and capabilities so that they can result to positive performance (Belinskaja \& Velickiene, 2015). These capabilities can be influenced by frequent employee trainings on risk management (Nanthuru, Pingfeng, Guihua, \& Mkonya, 2018). In this regard, SMEs need to embrace initiatives that can help them to forge strategic collaborations with key stakeholders aiming at accessing resources, knowledge, and capabilities (Zhai, Sun, Tsai, Wang, Zhao, \& Chen, 2018).

In order to influence their performance, SMEs need to define, and understand risk management strategies that work. These are the risk planning strategies, risk controlling strategies, and the strategic risk initiatives. This study seeks to ascertain whether these strategies contribute significantly to both cost level and production/output level of SMEs. The intention of this study is to draw lessons based on the business practices of Tanzania-based small and medium-sized bakeries whose products have been experiencing a growing demand in Tanzania (Bennett, Naziri, Mahende, \& Towo, 2012). The Tanzanian food industry, in which bakeries operate, is regarded as a major source of employment (URT \& UNIDO, 2012). The food sector is also directly linked with agriculture, a sector that significantly impacts the Tanzania economy (Chongela, 2015). We therefore seek to answer the following questions: 
- Does risk planning influence the cost level, and output level of Tanzania-based bakeries under the moderation of the bakery age, and the gender of the bakery owner/manager respectively?

- Does risk controlling influence the cost level, and output level of Tanzania-based bakeries under the moderation of the bakery age, and the gender of the bakery owner/manager respectively?

- Do strategic risk initiatives influence the cost level, and output level of Tanzania-based bakeries under the moderation of the bakery age, and the gender of the bakery owner/manager respectively?

\section{Literature Review}

Enterprise Risk Management in SMEs: Enterprise risk management (ERM) is a crucial aspect of corporate governance (Sprčić, Kožul, \& Pecina, 2015) that supports businesses in predicting risks and establishing tradeoffs between costs and earnings (Zou \& Hassan, 2015). By adopting ERM, enterprises are likely to identify possible risks and develop relevant controlling techniques (Soltanizadeh, Rasid, Golshan, Quoquab, \& Basiruddin, 2014; Nocco \& Stulz, 2006) aiming at managing risks and not eliminating them (Fadun, 2013). ERM involves all members of an organisation in developing strategies that identify and manage possible risks (Nocco \& Stulz, 2006; COSO, 2004; Harner, 2010) particularly the strategic, operational, and financial risks (Harner, 2010; Zou \& Hassan, 2015; Sprčić, Kožul, \& Pecina, 2015) or other risks depending on the characteristics of the industry (Nocco \& Stulz, 2006). Strategic risks are mainly associated with product development, competition, and customers. Financial risks are mainly linked to currency, price, liquidity, credit, and interest rate (Sprčić, Kožul, \& Pecina, 2015). Operational risks are heavily connected with business operations such as the internal processes, human capital, and external events (Basel Committee on Banking Supervision, 2005).

The relationship between risk management and SME performance is apparent (Kehinde, Opeyemi, Benjamin, Adedayo, \& Abel, 2017). Risk management helps SMEs to assess and make risky decision aimed at influencing their financial performance (Belinskaja \& Velickiene, 2015). Understanding of risk management plays a vital role in influencing SMEs' capabilities in managing uncertainties (Crovini, 2017), and disturbances to their operations (Verbano \& Venturini, 2013). However, the SME owners/managers, who are the key actors in the risk management process (Zoghi, 2017; Belinskaja \& Velickiene, 2015), have little understanding on risk management (Agrawal, 2016). In this regard, owners/managers and their employees need to acquire the risk management knowledge in order to manage the multiple aspects of their businesses (Lukianchuk, 2015; Falkner \& Hiebl, 2015). Additionally, the risk management process should involve all members of an enterprise (Agrawal, 2016).

SMEs have been facing financial, operational, and strategic risks (Zoghi, 2017). Risk management techniques, depending on the form of risks, should be adopted by SMEs in order to manage these risks. These would for instance, include compliance on safety standards, regular employee trainings in risk management, and their readiness to adopt risk planning techniques that can support the management of business and operational crises related to order management, production, and payment (Belinskaja \& Velickiene, 2015). However, a successful risk management process depends on the improved internal environments that facilitate the sharing of information on risks and their respective controlling tactics. Such environments are likely to influence SME's performance (Jenya \& Sandada, 2017). However, most of the SMEs put little emphasis on the risk management process (Brustbauer, 2016). They also face difficulties in intertwining risk management and other business processes within their entities (Gorzeń-Mitka, 2015). However, SMEs do sometimes consult friends or other people with deeper risk knowledge and experience, or outsource risk management assignments whenever they encounter risk management problems (Belinskaja \& Velickiene, 2015). Additionally, their involvement in risk management tasks is very infrequent. They mainly develop risk management techniques based on experience, and brainstorming (Zoghi, 2017). Some do manage risks through an emergency plan (Falkner \& Hiebl, 2015). This plan informs the SME capabilities in managing risks, and can be used by lenders or investors in assessing the future performance of SMEs (Lukianchuk, 2015). However, most of their risk management processes are not documented (Zoghi, 2017).

SMEs need to enhance their capabilities in accessing markets, responding to the changes and challenges from the business environments, and in developing and executing business plans (Agrawal, 2016; Belinskaja \& Velickiene, 2015). Through these plans, they can access resources such as big loans. However, the 
development and execution of these plans need the support of enhanced risk management strategies (Belinskaja \& Velickiene, 2015). These strategies can be influenced by the adoption of ERM. SMEs are encouraged to adopt ERM (Brustbauer, 2016) due to its significance in influencing business performance, and competitiveness (Yang, Ishtiaq, \& Anwar, 2018; Brustbauer, 2016; Lukianchuk, 2015; Agrawal, 2016; Smit \& Watkins, 2012). However, the adoption of ERM depends on the SMEs' readiness to train their workforce in managing risks and intertwining them with their daily business operations (Crovini, 2017; Kehinde, Opeyemi, Benjamin, Adedayo, \& Abel, 2017; Brustbauer, 2016).

Transaction Cost Economics in SMEs: The focus of Transaction Cost Economics (TCE) is on transactions and modes of governance (Williamson, 1997). TCE considers transactions as an essential unit of analysis (Riordan \& Williamson, 1985; Williamson, 1997; Williamson, 1999). TCE tells that "the governance of exchange agreements between economic actors is costly" (Leiblein, 2003, p. 939). That is why TCE emphasizes the need to have a governance form that minimizes costs (Das \& Teng, 2000; Williamson, 1979; Leiblein, 2003). It advocates for the enterprises' commitment in having effective operation and structure and at the same time attaining efficiency (Williamson, 1981). One of the central questions in TCE is whether efficiency can be attained when a transaction takes place within a firm or outside it (Geyskens, Steenkamp, \& Kumar, 2006). TCE assumes that enterprises have the capabilities to foresee potential hazards, and integrate them into the organizational design (Williamson, 1999). However, the theory asserts that enterprises face difficulties in accurately foretelling and planning for the future. This is why enterprises struggle in accessing and analyzing information about the economic actor(s) and the contracting environment (Leiblein, 2003). TCE assumes that economic actor(s) are disposed to use dishonesty as a mechanism to individual gains in transactions (Williamson, 1973).

SMEs strive to manage costs. They strive to adopt mechanisms that can maximize their profitability with low costs (Agburu, Anza, \& Iyortsuun, 2017). Poor cost management is likely to attract risks, leading to SME unprofitability (Nikolaeva \& Pletnev, 2016). Therefore, effective cost management, and efficiency can be attained when effective governance mechanisms are adopted (Lopez-Perez, Perez-Lopez, \& Rodriguez-Ariza, 2013). The adoption can be done by the SME owners/managers since they are the key decision makers in their organizations (Priyanath \& Premaratne, 2015). Nevertheless, the SMEs' small structures have higher chances of influencing performance (Lopez-Perez, Perez-Lopez, \& Rodriguez-Ariza, 2013). Such performance can be translated in terms of cost reduction. On this regard, Shahzad (2017) argues that both relational and structural governance approaches have direct impact in the reduction of transaction cost.

The transaction cost mediates the link between entrepreneurial orientation and SME growth. It also mediates the link between social capital and SME growth (Wimba, Budhi, Yasa, \& Saskara, 2015). Through social capital, SMEs can easily reduce monitoring costs (Priyanath \& Premaratne, 2015). For example, in Tanzania, SMEs do manage transaction costs related to information, monitoring, and negotiation (Rasheli, 2016). Negotiation costs comprise of costs related to transaction details, obligations of exchange partners, transaction arrangements, and benefit structure. Therefore, SMEs need to evaluate information before making any decision. However, SMEs have little capabilities in assessing complex information. Given this context, they need capabilities in mitigating opportunism from exchange partners. Exchange partners would be suppliers, customers, and any other relevant player involved in transaction. Through social relationships, SMEs are likely to access information that mitigates opportunism and which ultimately reduces transaction costs (Priyanath \& Premaratne, 2015).

Risk-taking and SME Performance: The adoption of risk-taking strategies can have great influence on SME performance (Wambugu, Gichira, Wanjau, \& Mung'atu, 2015; Naldi, Nordqvist, Sjöberg, \& Wiklund, 2007). These strategies are characterized as the readiness to invest in high risk businesses that expect significant returns (Wambugu, Gichira, Wanjau, \& Mung'atu, 2015; Fairoz, Hirobumi, \& Tanaka, 2010), the capabilities of SMEs to take calculated risks, develop a backup plan, and the readiness to exploit opportunities in uncertainty (Maladzhi, 2015; Fairoz, Hirobumi, \& Tanaka, 2010). They also involve the readiness of SMEs to acknowledge ideas from key stakeholders such as customers (Maladzhi, 2015), the use of huge resources for growth ambitions such as readiness to take big loans (Wambugu, Gichira, Wanjau, \& Mung'atu, 2015), revealing boldness in business operations aiming at achieving business objectives (Fairoz, Hirobumi, \& Tanaka, 2010), continuous searching of opportunities such as adopting new technology in exploring business opportunities 
(Wambugu, Gichira, Wanjau, \& Mung'atu, 2015), and creating an environment that encourages innovation, and creative solutions (Maladzhi, 2015). There is little risk-taking and SME performance research that is based on the bakery industry. We characterize risk-taking strategies as risk planning, risk controlling, and strategic risk initiatives, and seek to establish their contribution on bakery performance: level of operation and production costs, and production/output level, under the moderation of bakery age, and owner's/manager's gender respectively. The preference on firm age has been influenced by Lee \& Marvel (2009); Valdez-Juárez, García-Pérez de Lema, \& Maldonado-Guzmán, (2016); Voulgaris, Asteriou, \& Agiomirgianakis (2003); Rosenbusch, Brinckmann, \& Bausch (2011); Rosli \& Sidek (2013); and Salojärvi, Furu, \& Sveiby (2005). Additionally, gender is also preferred based on the fact that the presence of women in bakery industry is significant (Quaye, Onumah, Tortoe, Akonor, \& Buckman, 2018), and are able to identify the relationship between risk management and firm's planning and controlling tasks than men (GorzeńMitka, 2015). Nevertheless, male SME owners/managers demonstrate higher risk appetite than female owners/managers (Falkner \& Hiebl, 2015). In this regard, the role of gender in risk management is apparent.

Although sales growth (Fairoz, Hirobumi, \& Tanaka, 2010; Naldi, Nordqvist, Sjöberg, \& Wiklund, 2007; Wambugu, Gichira, Wanjau, \& Mung'atu, 2015), profitability (Wambugu, Gichira, Wanjau, \& Mung'atu, 2015; Naldi, Nordqvist, Sjöberg, \& Wiklund, 2007; Fairoz, Hirobumi, \& Tanaka, 2010), and productivity (Maladzhi, 2015) have been widely used as performance indicators in most of the risk-taking and SME performance studies, our assumption of adopting cost level is based on the fact that profitability cannot be attained if cost management measures are not in place. We also adopt the output level after associating sales level with both quality output and productivity. Our study adopts a large sample based on Naldi, Nordqvist, Sjöberg, \& Wiklund (2007), Amin (2015), and Kiprotich, Kimosop, Kemboi, \& Chepkwony (2015). We also involve random selection as adopted by Amin (2015), and stratification as used by Naldi, Nordqvist, Sjöberg, \& Wiklund (2007). We also involve questionnaires (Maladzhi, 2015; Wambugu, Gichira, Wanjau, \& Mung'atu, 2015; Kiprotich, Kimosop, Kemboi, \& Chepkwony, 2015; Amin, 2015), and interviews (Fairoz, Hirobumi, \& Tanaka, 2010) in collecting data. These data are analyzed using the principal component analysis, and moderator analysis whereby a hierarchical regression analysis is involved. We draw this experience from the studies of Maladzhi (2015); Wambugu, Gichira, Wanjau, \& Mung'atu (2015); and Naldi, Nordqvist, Sjöberg, \& Wiklund (2007) that adopted a factor analysis, and the studies of Wambugu, Gichira, Wanjau, \& Mung'atu (2015); and Amin (2015) that adopted a structural equation modelling. Our preference on the moderator analysis is also based on the use of a multiple regression analysis as used by Fairoz, Hirobumi, \& Tanaka (2010); Naldi, Nordqvist, Sjöberg, \& Wiklund (2007); and Kiprotich, Kimosop, Kemboi, \& Chepkwony (2015).

Risk-taking Practices in Bakeries: Bakeries have been facing risks associated with planning and growth (Sum \& Mahussin, 2017). Food enterprises need capabilities to foretell market needs in order to drive customer satisfaction (Cantaleano, Rodrigues, \& Martins, 2018). Therefore, a contingency plan is of paramount importance in the risk management process (Ariyanti \& Andika, 2016). Strategic plans are to a great extent developed by the owners/managers than other employees (Mithwani, 2015). The plans of most of the small bakeries are based on experience (Van Der Spiegel, Luning, De Boer, Ziggers, \& Jongen, 2005). There is also low risk management training in bakeries (Alexopoulos, Kavadi, Bakoyannis, \& Papantonopoulos, 2009). They also reveal low capabilities in managing essential business operations (Louw, Troskie, \& Geyser, 2013). In this case, bakeries have the responsibility of training their workforce especially on food chain issues aiming at propelling business performance (Marques, Matias, Teixeira, \& Brojo, 2012). These trainings should be intertwined with risk issues in order to interconnect business operations with risk management processes. Most of the risk issues are related with demand, raw materials, and recession (Ariyanti \& Andika, 2016), ergonomics, hygiene, machinery, and logistics (Alexopoulos, Kavadi, Bakoyannis, \& Papantonopoulos, 2009). They also face financial, operational, and strategic risks. They also face risks associated with planning, sustainability, and the workforce (Sum \& Mahussin, 2017). There are also workrelated risks in bakeries which are mainly influenced by managing big load, temperatures, noise, stress, and highly demanding and time consuming tasks (Alexopoulos, Kavadi, Bakoyannis, \& Papantonopoulos, 2009). These risks negatively affect cost management especially the rising costs of raw materials, logistics, and costs related to machinery. Also, risks in bakeries negatively affect production output level, and revenues (Sum \& Mahussin, 2017). 
Bakery products face forms of spoilage (Smith, Daifas, El-Khoury, Koukoutsis, \& El-Khoury, 2004) mostly caused by bacteria and fungi (Pundir \& Jain, 2011). Apart from microbiological spoilage, they also face physical and chemical spoilage (Smith, Daifas, El-Khoury, Koukoutsis, \& El-Khoury, 2004). In this regard, bakeries need to integrate an advanced technology in producing safe and healthy products (Marques, Matias, Teixeira, \& Brojo, 2012). They also need to improve the working conditions for their workforce in order to influence competiveness (Rocha, Oliveira, Campos, Oliveira, \& Saldanha, 2009). Through enhanced working environments, bakeries are likely to control most of the work-related risks. One of the techniques is to provide employee training in risk management (Aguwa \& Arinze-Onyia, 2014).

Most of the strategic risks in bakeries are associated with failures in planning, poor customer relationship management, and weak financial management practices (Sum \& Mahussin, 2017). Therefore, capabilities to manage costs, cash flow, and to acquire and utilize knowledge on bakery operations need to be enhanced (Louw, Troskie, \& Geyser, 2013). In this case, risks related with demand can be mitigated by effective customer relationship management techniques whose primary goal is to acquire and utilize information that is used to develop and execute plans on customer needs and business operations (Ariyanti \& Andika, 2016). Additionally, bakeries can also manage customer needs if they offer more innovative product choices (Fejza, Ismajli, \& Misini, 2013) such as nutritional and health products (Brodowska, Guzek, \& Wierzbicka, 2014). However, the adoption of ERM is of paramount importance in addressing most of the risks (Ariyanti \& Andika, 2016).

Bakeries lack capabilities to conduct market research and competition diagnosis (Fejza, Ismajli, \& Misini, 2013). These researches are crucial in understanding the business environments, identifying risks, and in assessing bakery performance (Oleiniuc, 2012). The positive performance is likely to be achieved if bakeries attain capabilities in managing competition, develop more quality products, enhance their distribution systems (Sum \& Mahussin, 2017), and improve their relationship with suppliers (Ariyanti \& Andika, 2016). To a great extent, bakeries have the responsibility of designing proper mechanisms that enhance their working environments in order to manage risks related to product quality, production processes and output, accidents, and work-related illness (Rocha, Oliveira, Campos, Oliveira, \& Saldanha, 2009). However, an effective designing of these mechanisms depends on the support from bakery owners/managers and the respective governance structures (Mithwani, 2015).

Conceptual Framework: We have defined our independent variables characterizing risk planning as the commitment of bakeries to ensure that they have the relevant knowledge and technical know-how in foreseeing potential hazards (PI1); the commitment of bakeries to integrate potential hazards in their day to day operations (PI2); the commitment of bakeries to make an in-depth analysis before entering into any contract with any supplier or business partner (PI3); the commitment of bakeries to frequently find whether there are any changes in their business environment related to pricing, technology, products, policies, and legal requirements (PI4); and the capabilities of bakeries to develop and use a backup plan whenever unexpected changes in their business and operating environment occur (PI5). Under the risk controlling, the study defines the independent variables as the commitment of bakeries to replace bakery appliances and other equipments with new ones as per technical advice (CI1); the commitment of bakeries to frequently evaluate the performance of their contracts with their suppliers, agents or business partners (CI2); the commitment of bakeries to frequently test the performance of their product development processes (CI3); the commitment of bakeries to frequently test the performance of their operating procedures (CI4); and the commitment of bakeries to frequently request for feedback from customers with regard to their product performance in terms of price, packaging, ingredients, and taste (CI5). Under the strategic risk initiatives, the study defines the independent variables as the commitment of bakeries to frequently analyze the strengths and weaknesses of their major competitors (SI1); the commitment of bakeries to frequently request for feedback from employees about their satisfaction level against their working environment (SI2); the readiness of bakeries to incur any additional cost to meet their customers' demands (SI3); the readiness of bakeries to incur any additional cost to comply with the legal requirements (SI4); the readiness of bakeries to invest in any risky business that will yield significant returns (SI5); and the commitment of bakeries in applying and acquiring big loans (SI6). The moderator variables include the bakery age (A), and bakery owner's/manager's gender (G). The dependent variables are the cost level (CT), and output level (OT) as shown in Figure 1. 


\section{Figure 1}

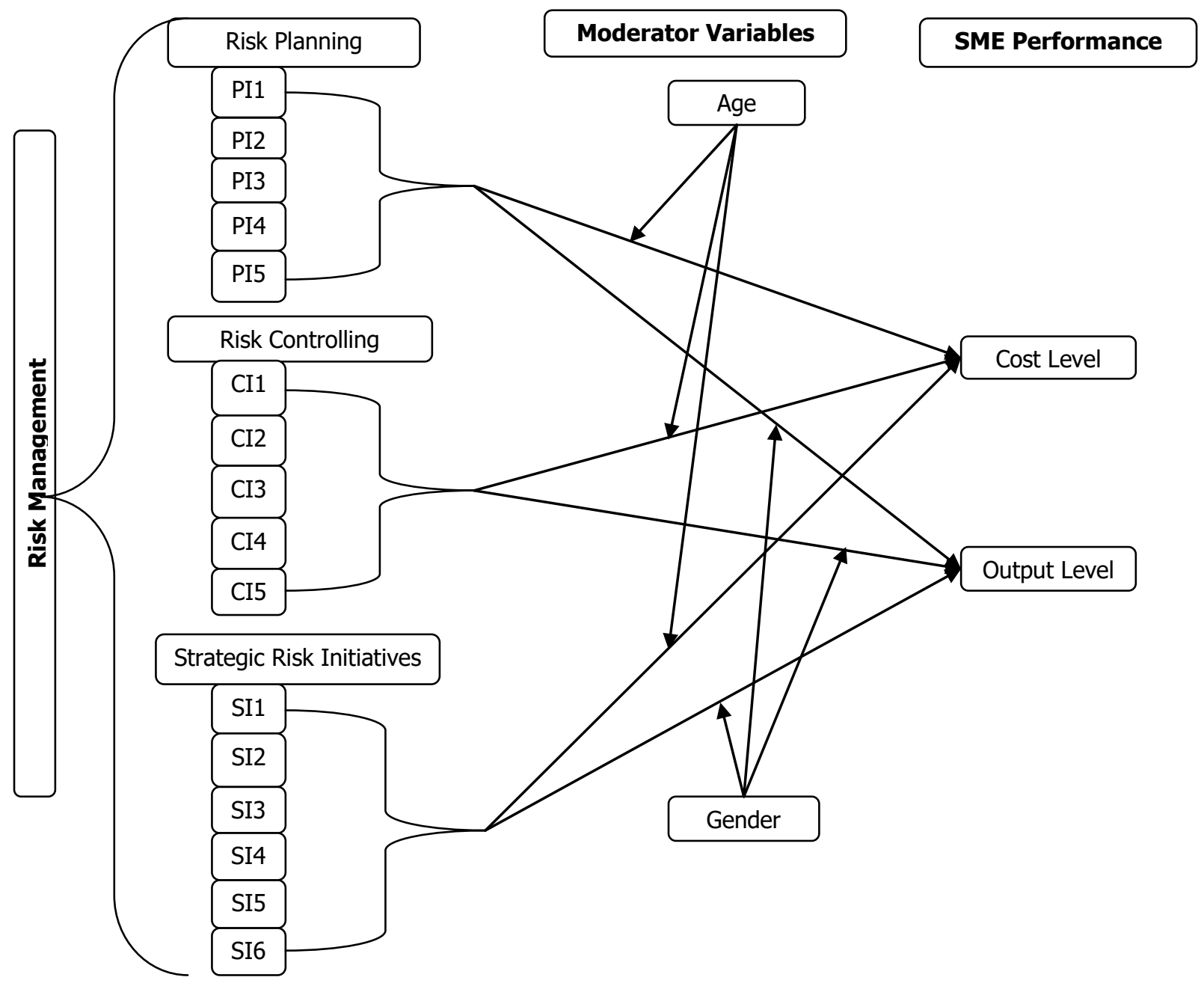

\section{Methodology}

Research Design and Sampling: This study adopted a concurrent nested design (Almeida, 2018) in which both quantitative and qualitative data were collected concurrently (Santos, Erdmann, Meirelles, Lanzoni, Cunha, \& Ross, 2017). The choice of the design was influenced by the fact that there was a predominance of an approach (Almeida, 2018). In this regard, the quantitative approach was predominant. The study took place in the United Republic of Tanzania that is made up of Mainland Tanzania, and Zanzibar. However, the study was based in Mainland Tanzania where Tanzania Food and Drugs Authority (TFDA) regulated the operations of bakeries. Currently, the administration of bakery operations has been shifted to the Tanzania Bureau of Standards (TBS). The Mainland Tanzania is the largest part of Tanzania with twenty six (26) geographical regions while Zanzibar comprises of five (5) regions. This study focused on registered bakeries only as its population. The population comprised of 359 registered small and medium-sized bakeries operating in Mainland Tanzania. The study relied on Krejcie \& Morgan's (1970) Table to determine a sample size. According to the Table, a population of 359 gives a sample size of 186 registered small and mediumsized bakeries. We also adopted a multi-stage sampling technique in which all the 26 regions of Mainland Tanzania were stratified into 7 geographical zones based on TFDA's zone classification. We thereafter adopted the probability proportional to size in order to establish the number of bakeries that are incorporated in the sample from each zone. Afterwards, we adopted the simple random sampling technique in order to identify bakeries from each zone. This resulted to 21 bakeries from Central Zone, 94 bakeries from 
Eastern Zone, 23 bakeries from Lake Zone, 23 bakeries from Northern Zone, 9 bakeries from Southern Zone, 12 bakeries from Southern Highlands Zone, and 4 bakeries from Western Zone. The multi-stage sampling technique was adopted due to the fact that it is useful in a study whose population is scattered over a wide area (Chauvet, 2015) such as Tanzania Mainland.

Data Collection and Analysis: A total of 186 questionnaires were distributed to the owners/managers of the bakeries. Each bakery received a questionnaire. We received a positive response from 161 bakeries as follows: 19 bakeries from Central Zone, 78 bakeries from Eastern Zone, 19 bakeries from Lake Zone, 22 bakeries from Northern Zone, 7 bakeries from Southern Zone, 12 bakeries from Southern Highlands Zone, and 4 bakeries from Western Zone. Additionally, we carried out in-depth interviews to 20 bakeries as follows: 3 bakeries from Central Zone, 10 bakeries from Eastern Zone, 3 bakeries from Lake Zone, 3 bakeries from Northern Zone, and 1 bakery from Southern Highlands Zone. Our data collection took place from November 2018 to February 2019. The responses based on the operations and practices that have been taking place in bakeries for a period of three years. The data analysis was done using the principal component analysis, qualitative content analysis (manifest analysis), and the moderator analysis.

Variables and Measurements: The responses of both the independent, and dependent variables were collected using the seven-point Likert scale. The moderator variables were grouped to form dichotomous variables. The bakery age is categorized as advanced age (AA), and basic age (BS). It is measured as AA (A>10years), and BA (A $\leq 10$ years). The bakery owner's/manager's gender is categorized as male (M), and female (F).

Validity and Reliability: The principal component analysis was run with all variables associated with risktaking strategies and confirmed that all variables (except SI6) had at least one correlation with another variable; where $r \geq 0.3$. Therefore, SI6 was removed and the PCA was re-run and it was revealed that all variables had at least one correlation with another variable. The overall KMO measure was 0.886 , and the Bartlett's Test of Sphericity was statistically significant, $p=0.000(p<0.0005)$ confirming that there was adequacy of sampling. Additionally, the rotated component matrix appeared to be a simple structure in which each variable had only one component that loads strongly on it. Also, each component loaded strongly on at least three variables. Therefore, validity was confirmed. On the other hand, the values of Cronbach's alpha were 0.837 (risk planning), 0.844 (risk controlling), and 0.821 (strategic risk initiatives). All these values were at least 0.700 signifying that in all cases, the scale was found to have a good level of internal consistency (DeVellis, 2003; Kline, 2005).

Testing for Assumptions: The major assumptions such as linearity, multicollinearity, unusual points, homoscedasticity, and normality were tested. Linearity was established by visual inspection of a scatterplot between: CT and PI1, OT and PI1; CT and PI2, OT and PI2; CT and PI3, OT and PI3; CT and PI4, OT and PI4; CT and PI5, OT and PI5; CT and CI1, OT and CI1; CT and CI2, OT and CI2; CT and CI3, OT and CI3; CT and CI4, OT and CI4; CT and CI5, OT and CI5; CT and SI1, OT and SI1; CT and SI2, OT and SI2; CT and SI3, OT and SI3; CT and SI4, OT and SI4; CT and SI5, OT and SI5. On the other hand, the study found that there was no evidence of multicollinearity. All the tolerance values were greater than 0.1 (the lowest were $0.111,0.111,0.114,0.108$, $0.107,0.111,0.113,0.120,0.110,0.122,0.113,0.101,0.108,0.108,0.113,0.103,0.100,0.108,0.107,0.107$, $0.107,0.102,0.103,0.110,0.103,0.107,0.104,0.103,0.100,0.102)$. All their corresponding VIF values were less than 10 (the greatest were 8.989, 9.001, 8.750, 9.296, 9.349, 9.003, 8.833, 8.323, 9.099, 8.172, 8.841, 9.915, 9.291, 9.280, 8.865, 9.693, 9.989, 9.288, 9.369, 9.331, 9.332, 9.801, 9.693, 9.130, 9.703, 9.350, 9.631, $9.739,9.973,9.762$ ). Also, there were neither outliers nor influential case. This is because; there was no any standard deviations $> \pm 3$, no leverage value $>0.04969$, and no cook's distance $>1$. It was also found that there was homoscedasticity based on the visual inspection of the studentized residuals plotted against the predicted values for bakeries with AA and BA between: CT and PI1; CT and PI2; CT and PI3; CT and PI4; CT and PI5; CT and CI1; CT and CI2; CT and CI3; CT and CI4; CT and CI5; CT and SI1; CT and SI2; CT and SI3; CT and SI4; CT and SI5. There was also homoscedasticity based on the visual inspection of the studentized residuals plotted against the predicted values for bakeries with $\mathrm{M}$ and $\mathrm{F}$ between: OT and PI1; OT and PI2; OT and PI3; OT and PI4; OT and PI5; OT and CI1; OT and CI2; OT and CI3; OT and CI4; OT and CI5; OT and SI1; OT and SI2; OT and SI3; OT and SI4; OT and SI5. Additionally, in all cases, the Normal Q-Q Plot of Studentized Residual was used and found that studentized residuals were normally distributed. 


\section{Findings}

As explained earlier, the PCA was employed to confirm variables that explain the risk planning, risk controlling, and strategic risk initiatives. Three components were retained. The PCA confirmed that risk planning is characterized by PI1, PI2, PI3, PI4, and PI5 while risk controlling is characterized by CI1, CI2, CI3, CI4, and CI5. It also confirmed that strategic risk initiatives are characterized by SI1, SI2, SI3, SI4, and SI5. Nevertheless, based on the qualitative content analysis (manifest analysis), the interviews confirm that there is still little understanding of risk management practices among bakeries in Tanzania. However, most of the owners/managers confirmed that they had been undergoing necessary risk management trainings with the aim of increasing their capabilities in risk planning, controlling, and in making strategic risk decisions. According to the interviews, they were keeping on finding the possible "dangers" that may occur in their operating environment, or in the external environment relating to their business such as technology, pricing of raw materials and finished bakery products, and all matters pertaining to compliance. This was being done by consulting all members of the bakery, and their stakeholders such as agents, supermarkets, stores, hotel, restaurants, suppliers, individual customers, and business partners. Within their operating environment, 0bakeries take time to foresee possible "dangers" that may affect the production of bakeries, transportation, and the contracts between the bakeries and their stakeholders. However, most of them do not make an appropriate documentation of their plans. Also, according to the interviews, bakeries keep on controlling risks by abiding by the technical advice on the operations and management of bakery appliances and other relevant equipments, and on development and operations of business contracts with their stakeholders. As the findings reveal, most of the bakeries were ready to analyze their operations and production processes and practices in order to fix all the relevant problems on time. To a great extent, the bakeries were consulting and interviewing their stakeholders in order to acquire the relevant information regarding the challenges, weaknesses, and other operational problems in order to fix them before they grew out of proportions thus negatively affecting their business. Also, according to the interviews, bakeries were aware of the fact that unexpected changes could affect their performance. This is why they were frequently making self-evaluations and adapting to the changes and relevant solutions on time. They were also conducting a competitor diagnosis in order to understand their weaknesses and strengths and improve accordingly. According to the interviews, they were financing these tasks with a clear understanding that failure to do so might result to unbearable costs in future. This was their strategy of preventing problems before they occur.

Risk Planning and Bakery Performance: A hierarchical multiple regression was run to assess the increase in variation explained by the addition of an interaction term between PI1 and A; PI1 and G; PI2 and A; PI2 and G; PI3 and A; PI3 and G; PI4 and A; PI4 and G; PI5 and A; and PI5 and G to a main effects model. A moderates the effect of PI1 on CT, as evidenced by a statistically significant increase in total variation explained of 3.5\%, $F(1,157)=5.916, p=0.016$. It also moderates the effect of PI 2 on CT, as evidenced by a statistically significant increase in total variation explained of $2.9 \%, F(1,157)=4.934, p=0.028$. It was also revealed that $\mathrm{A}$ moderates the effect of PI3 on CT, as evidenced by a statistically significant increase in total variation explained of $5.1 \%, F(1,157)=8.861, p=0.003$. It also moderates the effect of PI4 on CT, as evidenced by a statistically significant increase in total variation explained of $4.0 \%, F(1,157)=6.871, p=0.010$. Similarly, A moderates the effect of PI5 on CT, as evidenced by a statistically significant increase in total variation explained of $4.1 \%, F(1,157)=7.053, p=0.009$. On the other hand, the findings reveal that G moderates the effect of PI1 on OT, as evidenced by a statistically significant increase in total variation explained of $3.7 \%, F(1$, $157)=7.209, p=0.008$. It also moderates the effect of PI2 on OT, as evidenced by a statistically significant increase in total variation explained of $2.9 \%, F(1,157)=5.569, p=0.020$. Also, the findings reveal that $\mathrm{G}$ moderates the effect of PI3 on OT, as evidenced by a statistically significant increase in total variation explained of $3.4 \%, F(1,157)=6.046, p=0.015$. It also moderates the effect of PI4 on OT, as evidenced by a statistically significant increase in total variation explained of $2.8 \%, F(1,157)=5.282, p=0.023$. Similarly, $\mathrm{G}$ moderates the effect of PI5 on OT, as evidenced by a statistically significant increase in total variation explained of $3.8 \%, F(1,157)=6.490, p=0.012$.

The simple slopes analysis revealed that the linear relationship between CT and PI1 in bakeries with AA $(0.164 \pm 0.217)$, was not statistically significant $p=0.451$. However, the simple slopes analysis revealed that the linear relationship between CT and PI1 in bakeries with BA $(-0.467 \pm 0.141)$, was statistically significant, $p=0.001$. The relationship is negative. The coefficient of the interaction term $(0.631 \pm 0.259)$ was statistically 
significant $(p=0.016)$ indicating that A moderates the relationship between CT and PI1. On the other hand, the simple slopes analysis revealed that the linear relationship between OT and PI1 in bakeries with M 0.351 $\pm 0.061)$, was statistically significant, $p=0.000(p<0.0005)$. However, the simple slopes analysis revealed that the linear relationship between OT and PI1 in bakeries with F $(0.075 \pm 0.082)$, was not statistically significant, $p=0.361$. The coefficient of the interaction term $(0.276 \pm 0.103)$ was statistically significant $(p=$ 0.008 ) indicating that $\mathrm{G}$ moderates the relationship between OT and PI1. Again, the simple slopes analysis revealed that the linear relationship between CT and PI2 in bakeries with AA (0.077 \pm 0.213$)$, was not statistically significant $p=0.718$. However, the simple slopes analysis revealed that the linear relationship between CT and PI2 in bakeries with BA $(-0.497 \pm 0.146)$, was statistically significant, $p=0.001$. The relationship is negative. The coefficient of the interaction term $(0.574 \pm 0.258)$ was statistically significant $(p$ $=0.028$ ) indicating that A moderates the relationship between CT and PI2. On the other hand, the simple slopes analysis revealed that the linear relationship between OT and PI2 in bakeries with M $(0.172 \pm 0.078)$, was statistically significant, $p=0.029$. However, the simple slopes analysis revealed that the linear relationship between OT and PI2 in bakeries with F $(0.438 \pm 0.082)$, was statistically significant, $p=0.000(p$ $<0.0005)$. The coefficient of the interaction term $(0.266 \pm 0.113)$ was statistically significant $(p=0.020)$ indicating that G moderates the relationship between OT and PI2. Again, the simple slopes analysis revealed that the linear relationship between CT and PI3 in bakeries with AA $(0.295 \pm 0.214)$, was not statistically significant $p=0.170$. However, the simple slopes analysis revealed that the linear relationship between CT and PI3 in bakeries with BA $(-0.447 \pm 0.128)$, was statistically significant, $p=0.001$. The relationship is negative. The coefficient of the interaction term $(0.742 \pm 0.249)$ was statistically significant $(p=0.003)$ indicating that A moderates the relationship between CT and PI3. On the other hand, the simple slopes analysis revealed that the linear relationship between OT and PI3 in bakeries with M (0.062 \pm 0.052$)$, was not statistically significant, $p=0.238$. However, the simple slopes analysis revealed that the linear relationship between OT and PI3 in bakeries with F (0.288 \pm 0.075$)$, was statistically significant, $p=0.000(p<0.0005)$. The coefficient of the interaction term $(0.226 \pm 0.092)$ was statistically significant $(p=0.015)$ indicating that $\mathrm{G}$ moderates the relationship between OT and PI3. Again, the simple slopes analysis revealed that the linear relationship between CT and PI4 in bakeries with AA $(0.075 \pm 0.189)$, was not statistically significant $p=$ 0.692. However, the simple slopes analysis revealed that the linear relationship between CT and PI4 in bakeries with BA $(-0.583 \pm 0.165)$, was statistically significant, $p=0.001$. The relationship is negative. The coefficient of the interaction term $(0.658 \pm 0.251)$ was statistically significant $(p=0.010)$ indicating that A moderates the relationship between CT and PI4. On the other hand, the simple slopes analysis revealed that the linear relationship between OT and PI4 in bakeries with M $(0.339 \pm 0.061)$, was statistically significant, $p$ $=0.000(p<0.0005)$. However, the simple slopes analysis revealed that the linear relationship between OT and PI4 in bakeries with F $(0.109 \pm 0.079)$, was not statistically significant, $p=0.169$. The coefficient of the interaction term $(0.230 \pm 0.100)$ was statistically significant $(p=0.023)$ indicating that G moderates the relationship between OT and PI4. Again, the simple slopes analysis revealed that the linear relationship between CT and PI5 in bakeries with AA $(0.339 \pm 0.223)$, was not statistically significant $p=0.131$. However, the simple slopes analysis revealed that the linear relationship between CT and PI5 in bakeries with BA ($0.379 \pm 0.153$ ), was statistically significant, $p=0.014$. The relationship is negative. The coefficient of the interaction term $(0.718 \pm 0.270)$ was statistically significant $(p=0.009)$ indicating that A moderates the relationship between CT and PI5. On the other hand, the simple slopes analysis revealed that the linear relationship between OT and PI5 in bakeries with M $(0.061 \pm 0.087)$, was not statistically significant, $p=$ 0.487 . However, the simple slopes analysis revealed that the linear relationship between OT and PI5 in bakeries with $\mathrm{F}(0.433 \pm 0.117)$, was statistically significant, $p=0.000(p<0.0005)$. The coefficient of the interaction term $(0.372 \pm 0.146)$ was statistically significant $(p=0.012)$ indicating that $\mathrm{G}$ moderates the relationship between OT and PI5.

Risk Controlling and Bakery Performance: A hierarchical multiple regression was run to assess the increase in variation explained by the addition of an interaction term between CI1 and A; CI1 and G; CI2 and A; CI2 and G; CI3 and A; CI3 and G; CI4 and A; CI4 and G; CI5 and A; and CI5 and G to a main effects model. A moderates the effect of CI1 on CT, as evidenced by a statistically significant increase in total variation explained of $3.3 \%, F(1,157)=5.761, p=0.018$. It also moderates the effect of CI2 on CT, as evidenced by a statistically significant increase in total variation explained of $4.0 \%, F(1,157)=6.880, p=0.010$. It was also revealed that A moderates the effect of $\mathrm{CI} 3$ on $\mathrm{CT}$, as evidenced by a statistically significant increase in total variation explained of $3.8 \%, F(1,157)=6.504, p=0.012$. It also moderates the effect of CI4 on CT, as 
evidenced by a statistically significant increase in total variation explained of $3.3 \%, F(1,157)=5.569, p=$ 0.020. Similarly, A moderates the effect of CI5 on CT, as evidenced by a statistically significant increase in total variation explained of $6.5 \%, F(1,157)=11.466, p=0.001$. On the other hand, the findings reveal that $\mathrm{G}$ moderates the effect of CI1 on OT, as evidenced by a statistically significant increase in total variation explained of $2.9 \%, F(1,157)=5.506, p=0.020$. It also moderates the effect of CI2 on OT, as evidenced by a statistically significant increase in total variation explained of $3.1 \%, F(1,157)=5.388, p=0.022$. Also, the findings reveal that $\mathrm{G}$ moderates the effect of $\mathrm{CI} 3$ on $\mathrm{OT}$, as evidenced by a statistically significant increase in total variation explained of $3.4 \%, F(1,157)=6.778, p=0.010$. It also moderates the effect of CI4 on OT, as evidenced by a statistically significant increase in total variation explained of $4.1 \%, F(1,157)=7.171, p=$ 0.008. Similarly, G moderates the effect of CI5 on OT, as evidenced by a statistically significant increase in total variation explained of $3.1 \%, F(1,157)=5.601, p=0.019$.

The simple slopes analysis revealed that the linear relationship between CT and CI1 in bakeries with AA $(0.161 \pm 0.220)$, was not statistically significant $p=0.465$. However, the simple slopes analysis revealed that the linear relationship between CT and CI1 in bakeries with BA $(-0.472 \pm 0.146)$, was statistically significant, $p=0.001$. The relationship is negative. The coefficient of the interaction term $(0.633 \pm 0.264)$ was statistically significant ( $p=0.018$ ) indicating that A moderates the relationship between CT and CI1. On the other hand, the simple slopes analysis revealed that the linear relationship between OT and CI1 in bakeries with M $(0.334$ $\pm 0.068)$, was statistically significant, $p=0.000(p<0.0005)$. However, the simple slopes analysis revealed that the linear relationship between OT and CI1 in bakeries with F $(0.062 \pm 0.093)$, was not statistically significant, $p=0.507$. The coefficient of the interaction term $(0.272 \pm 0.116)$ was statistically significant $(p=$ 0.020 ) indicating that G moderates the relationship between OT and CI1. Again, the simple slopes analysis revealed that the linear relationship between CT and CI2 in bakeries with AA $(0.371 \pm 0.222)$, was not statistically significant $p=0.096$. However, the simple slopes analysis revealed that the linear relationship between CT and CI2 in bakeries with BA $(-0.309 \pm 0.135)$, was statistically significant, $p=0.023$. The relationship is negative. The coefficient of the interaction term $(0.680 \pm 0.259)$ was statistically significant $(p$ $=0.010$ ) indicating that A moderates the relationship between CT and CI2. On the other hand, the simple slopes analysis revealed that the linear relationship between OT and CI2 in bakeries with M (0.040 \pm 0.068$)$, was not statistically significant, $p=0.558$. However, the simple slopes analysis revealed that the linear relationship between OT and CI2 in bakeries with F (0.313 \pm 0.096$)$, was statistically significant, $p=0.001$. The coefficient of the interaction term $(0.273 \pm 0.118)$ was statistically significant $(p=0.022)$ indicating that G moderates the relationship between OT and CI2. Again, the simple slopes analysis revealed that the linear relationship between CT and CI3 in bakeries with AA $(0.219 \pm 0.182)$, was not statistically significant $p=$ 0.230 . However, the simple slopes analysis revealed that the linear relationship between CT and CI3 in bakeries with BA $(-0.400 \pm 0.161)$, was statistically significant, $p=0.014$. The relationship is negative. The coefficient of the interaction term $(0.619 \pm 0.243)$ was statistically significant $(p=0.012)$ indicating that $\mathrm{A}$ moderates the relationship between CT and CI3. On the other hand, the simple slopes analysis revealed that the linear relationship between OT and CI3 in bakeries with M $(0.367 \pm 0.058)$, was statistically significant, $p$ $=0.000(p<0.0005)$. However, the simple slopes analysis revealed that the linear relationship between OT and CI3 in bakeries with F $(0.109 \pm 0.080)$, was not statistically significant, $p=0.176$. The coefficient of the interaction term $(0.258 \pm 0.099)$ was statistically significant $(p=0.010)$ indicating that $\mathrm{G}$ moderates the relationship between OT and CI3. Again, the simple slopes analysis revealed that the linear relationship between CT and CI4 in bakeries with AA $(0.252 \pm 0.208)$, was not statistically significant $p=0.226$. However, the simple slopes analysis revealed that the linear relationship between CT and CI4 in bakeries with BA ($0.372 \pm 0.164$ ), was statistically significant, $p=0.025$. The relationship is negative. The coefficient of the interaction term $(0.624 \pm 0.264)$ was statistically significant $(p=0.020)$ indicating that A moderates the relationship between $\mathrm{CT}$ and $\mathrm{CI} 4$. On the other hand, the simple slopes analysis revealed that the linear relationship between OT and CI4 in bakeries with M $(-0.012 \pm 0.070)$, was not statistically significant, $p=$ 0.861 . However, the simple slopes analysis revealed that the linear relationship between OT and CI4 in bakeries with $\mathrm{F}(0.304 \pm 0.095)$, was statistically significant, $p=0.002$. The coefficient of the interaction term $(0.317 \pm 0.118)$ was statistically significant $(p=0.008)$ indicating that $\mathrm{G}$ moderates the relationship between OT and CI4. Again, the simple slopes analysis revealed that the linear relationship between CT and CI5 in bakeries with AA $(0.473 \pm 0.201)$, was statistically significant $p=0.020$. However, the relationship is positive. The simple slopes analysis revealed that the linear relationship between CT and CI5 in bakeries with BA ($0.379 \pm 0.152$ ), was statistically significant, $p=0.014$. The relationship is negative. The coefficient of the 
interaction term $(0.853 \pm 0.252)$ was statistically significant $(p=0.001)$ indicating that A moderates the relationship between CT and CI5. On the other hand, the simple slopes analysis revealed that the linear relationship between OT and CI5 in bakeries with M $(0.299 \pm 0.067)$, was statistically significant, $p=0.000(p$ $<0.0005)$. However, the simple slopes analysis revealed that the linear relationship between OT and CI5 in bakeries with $\mathrm{F}(0.059 \pm 0.076)$, was not statistically significant, $p=0.441$. The coefficient of the interaction term $(0.240 \pm 0.102)$ was statistically significant $(p=0.019)$ indicating that $G$ moderates the relationship between OT and CI5.

Strategic Risk Initiatives and Bakery Performance: A hierarchical multiple regression was run to assess the increase in variation explained by the addition of an interaction term between SI1 and A; SI1 and G; SI2 and A; SI2 and G; SI3 and A; SI3 and G; SI4 and A; SI4 and G; SI5 and A; and SI5 and G to a main effects model. A moderates the effect of SI1 on CT, as evidenced by a statistically significant increase in total variation explained of $3.3 \%, F(1,157)=5.631, p=0.019$. It also moderates the effect of SI2 on CT, as evidenced by a statistically significant increase in total variation explained of $2.9 \%, F(1,157)=5.014, p=0.027$. It was also revealed that A moderates the effect of SI3 on CT, as evidenced by a statistically significant increase in total variation explained of 7.7\%, $F(1,157)=14.161, p=0.000(p<0.0005)$. It also moderates the effect of SI 4 on $\mathrm{CT}$, as evidenced by a statistically significant increase in total variation explained of $3.6 \%, F(1,157)=6.208, p$ $=0.014$. Similarly, A moderates the effect of SI5 on CT, as evidenced by a statistically significant increase in total variation explained of $3.3 \%, F(1,157)=5.654, p=0.019$. On the other hand, the findings reveal that $\mathrm{G}$ moderates the effect of SI 1 on OT, as evidenced by a statistically significant increase in total variation explained of $2.8 \%, F(1,157)=4.878, p=0.029$. It also moderates the effect of SI2 on OT, as evidenced by a statistically significant increase in total variation explained of $3.1 \%, F(1,157)=5.907, p=0.016$. It was also revealed that G moderates the effect of SI3 on OT, as evidenced by a statistically significant increase in total variation explained of $6.2 \%, F(1,157)=10.877, p=0.001$. It also moderates the effect of SI4 on OT, as evidenced by a statistically significant increase in total variation explained of $3.9 \%, F(1,157)=6.878, p=$ 0.010. Similarly, G moderates the effect of SI5 on OT, as evidenced by a statistically significant increase in total variation explained of $3.9 \%, F(1,157)=8.444, p=0.004$.

The simple slopes analysis revealed that the linear relationship between CT and SI1 in bakeries with AA $(0.301 \pm 0.223)$, was not statistically significant $p=0.180$. However, the simple slopes analysis revealed that the linear relationship between CT and SI1 in bakeries with BA $(-0.332 \pm 0.145)$, was statistically significant, $p$ $=0.024$. The relationship is negative. The coefficient of the interaction term $(0.633 \pm 0.267)$ was statistically significant $(p=0.019)$ indicating that A moderates the relationship between CT and SI1. On the other hand, the simple slopes analysis revealed that the linear relationship between OT and SI1 in bakeries with M (0.246 $\pm 0.065)$, was statistically significant, $p=0.000(p<0.0005)$. However, the simple slopes analysis revealed that the linear relationship between OT and SI1 in bakeries with F $(0.019 \pm 0.080)$, was not statistically significant, $p=0.815$. The coefficient of the interaction term $(0.227 \pm 0.103)$ was statistically significant $(p=$ 0.029 ) indicating that G moderates the relationship between OT and SI1. Again, the simple slopes analysis revealed that the linear relationship between CT and SI2 in bakeries with AA $(0.226 \pm 0.231)$, was not statistically significant $p=0.328$. However, the simple slopes analysis revealed that the linear relationship between CT and SI2 in bakeries with BA $(-0.384 \pm 0.145)$, was statistically significant, $p=0.009$. The relationship is negative. The coefficient of the interaction term $(0.610 \pm 0.272)$ was statistically significant $(p$ $=0.027$ ) indicating that A moderates the relationship between CT and SI2. On the other hand, the simple slopes analysis revealed that the linear relationship between OT and SI2 in bakeries with M $(0.180 \pm 0.072)$, was statistically significant, $p=0.013$. The simple slopes analysis revealed that the linear relationship between OT and SI2 in bakeries with F $(0.472 \pm 0.096)$, was statistically significant, $p=0.000(p<0.0005)$. The coefficient of the interaction term $(0.292 \pm 0.120)$ was statistically significant $(p=0.016)$ indicating that G moderates the relationship between OT and SI2. Again, the simple slopes analysis revealed that the linear relationship between CT and SI3 in bakeries with AA $(0.132 \pm 0.175)$, was not statistically significant $p=$ 0.453. However, the simple slopes analysis revealed that the linear relationship between CT and SI3 in bakeries with BA $(-0.813 \pm 0.180)$, was statistically significant, $p=0.000(p<0.0005)$. The relationship is negative. The coefficient of the interaction term $(0.945 \pm 0.251)$ was statistically significant $(p=0.000$ or $p<$ 0.0005) indicating that A moderates the relationship between CT and SI3. On the other hand, the simple slopes analysis revealed that the linear relationship between OT and SI3 in bakeries with M (0.031 \pm 0.065$)$, was not statistically significant, $p=0.637$. The simple slopes analysis revealed that the linear relationship 
between OT and SI3 in bakeries with F $(0.425 \pm 0.100)$, was statistically significant, $p=0.000(p<0.0005)$. The coefficient of the interaction term $(0.394 \pm 0.119)$ was statistically significant $(p=0.001)$ indicating that $\mathrm{G}$ moderates the relationship between OT and SI3. Again, the simple slopes analysis revealed that the linear relationship between CT and SI4 in bakeries with AA $(0.124 \pm 0.195)$, was not statistically significant $p=$ 0.523 . However, the simple slopes analysis revealed that the linear relationship between CT and SI4 in bakeries with BA $(-0.544 \pm 0.185)$, was statistically significant, $p=0.004$. The relationship is negative. The coefficient of the interaction term $(0.668 \pm 0.268)$ was statistically significant $(p=0.014)$ indicating that A moderates the relationship between CT and SI4. On the other hand, the simple slopes analysis revealed that the linear relationship between OT and SI4 in bakeries with M $(0.103 \pm 0.057)$, was not statistically significant, $p=0.072$. The simple slopes analysis revealed that the linear relationship between OT and SI4 in bakeries with F $(0.392 \pm 0.094)$, was statistically significant, $p=0.000(p<0.0005)$. The coefficient of the interaction term $(0.289 \pm 0.110)$ was statistically significant $(p=0.010)$ indicating that G moderates the relationship between OT and SI4. Again, the simple slopes analysis revealed that the linear relationship between CT and SI5 in bakeries with AA $(0.302 \pm 0.221)$, was not statistically significant $p=0.173$. However, the simple slopes analysis revealed that the linear relationship between CT and SI5 in bakeries with BA ($0.326 \pm 0.145$ ), was statistically significant, $p=0.026$. The relationship is negative. The coefficient of the interaction term $(0.628 \pm 0.264)$ was statistically significant $(p=0.019)$ indicating that A moderates the relationship between CT and SI5. On the other hand, the simple slopes analysis revealed that the linear relationship between OT and SI5 in bakeries with M (0.272 \pm 0.069$)$, was statistically significant, $p=0.000(p$ $<0.0005)$. The simple slopes analysis revealed that the linear relationship between OT and SI5 in bakeries with $\mathrm{F}(0.623 \pm 0.099)$, was statistically significant, $p=0.000(p<0.0005)$. The coefficient of the interaction term $(0.350 \pm 0.121)$ was statistically significant $(p=0.004)$ indicating that G moderates the relationship between OT and SI5.

\section{Discussion}

Risk Planning and Bakery Performance: The findings tell that the age of the bakery moderates the relationship between bakeries' commitment in ensuring that they have the relevant knowledge and technical know-how in foreseeing potential hazards; and the cost level. It also moderates the relationship between bakeries' commitment in integrating potential hazards in their day to day operations; and the cost level. The findings also confirm that the age of the bakery moderates the relationship between bakeries' commitment in making an in-depth analysis before entering into any contract with any supplier or business partner; and the cost level. Similarly, the bakery age moderates the relationship between bakeries' commitment in frequently finding whether there are any changes in their business environment related to pricing, technology, products, policies, and legal requirements; and the cost level. It also moderates the relationship between bakeries' capabilities in developing and using a backup plan whenever unexpected changes in their business and operating environment occur; and the cost level. All these relationships exist in bakeries with basic age than in bakeries with an advanced age. This tells that the readiness and commitment of younger bakeries to adopt risk planning initiatives is higher than that of bakeries with an advanced age. Their readiness is likely to be attributed to by growth ambitions of most of the young firms. Ultimately, these commitments reduce their production and operation costs. On the other hand, the findings tell that the gender of the bakery owner/manager moderates the relationship between bakeries' commitment in ensuring that they have the relevant knowledge and technical know-how in foreseeing potential hazards; and the production/output level. This relationship exists in bakeries with male owners/managers than bakeries with female owners/managers. Also, gender moderates the relationship between bakeries' commitment in integrating potential hazards in their day to day operations; and the production/output level. Again, this relationship exists in bakeries with male owners/managers and those with female owners/managers. The findings also confirm that gender moderates the relationship between bakeries' commitment to make an in-depth analysis before entering into any contract with any supplier or business partner; and the production/output level. Conversely, this relationship exists in bakeries with female owners/managers than bakeries with male owners/managers. Similarly, gender moderates the relationship between bakeries' commitment in frequently finding whether there are any changes in their business environment related to pricing, technology, products, policies, and legal requirements; and the production/output level. This relationship exists in bakeries with male owners/managers than bakeries with female owners/managers. Also, gender moderates the relationship between bakeries' capabilities in developing and using a backup plan whenever unexpected 
changes in their business and operating environment occur; and the production/output level. This relationship exists in bakeries with female owners/managers than bakeries with male owners/managers. However, these relationships tell that both males' and females' commitments in adopting risk planning initiatives are significant. These commitments influence production/output performance. All the results corroborate with the fact that effective risk planning requires the competency of the SME workforce and their involvement in the planning process. The involvement of the workforce in decision-making process and readiness of the management to honor their ideas foster their motivation (Irawanto, 2015). Although SMEs that involve females in their top management teams are likely to achieve positive performance $(\mathrm{Wu}, \mathrm{Yao}, \&$ Muhammad, 2017), we argue that the commitment of the owners/managers and employees is more important than gender issues. We however argue that effective risk management in SMEs can be fuelled by the decision of owners/managers to adopt ERM. This is a source of SME's competitive advantage (Yang, Ishtiaq, \& Anwar, 2018). As revealed by the findings, young SMEs have higher chances of increasing their competitiveness if they adopt ERM in their business operations and risk planning strategies. This is because, firms with advanced age are bureaucratic, and inflexible (Pervan, Pervan, \& Ćurak, 2017).

Risk Controlling and Bakery Performance: The findings tell that the age of the bakery moderates the relationship between bakeries' commitment in replacing bakery appliances and other equipments with new ones as per technical advice; and the cost level. It also moderates the relationship between bakeries' commitment in frequently evaluating the performance of their contracts with their suppliers, agents or business partners; and the cost level. The findings also confirm that the bakery age moderates the relationship between bakeries' commitment in frequently testing the performance of their product development processes; and the cost level. Similarly, the bakery age moderates the relationship between bakeries' commitment in frequently testing the performance of their operating procedures; and the cost level. Again, all these relationships exist in bakeries with basic age than in bakeries with an advanced age. This tells that the readiness and commitment of younger bakeries to adopt risk controlling techniques is higher than that of bakeries with an advanced age. Their readiness is likely to be attributed to by growth ambitions of most of the young firms. Ultimately, this commitment reduces their production and operation costs. Again, the bakery age moderates the relationship between bakeries' commitment in frequently requesting for feedback from customers with regard to their product performance in terms of price, packaging, ingredients, and taste; and the cost level. The findings reveal that this relationship exists in bakeries with both basic age and advanced age. However, a positive relationship in bakeries with advanced age informs that their commitment to adopt risk controlling initiatives leads to an increase in production and operation costs. The negative relationship revealed in bakeries with a basic age tells that their commitment in adopting risk controlling initiatives influences a reduction in production and operation costs. This tells that the younger bakeries have more of the right risk controlling techniques than bakeries with an advanced age. We also argue that their commitment in adopting the right techniques is likely to be attributed to by growth ambitions of most of the young firms. On the other hand, the findings tell that the gender of the bakery owner/manager moderates the relationship between bakeries' commitment in replacing bakery appliances and other equipment with new ones as per technical advice; and the production/output level. This relationship exists in bakeries with male owners/managers than bakeries with female owners/managers. Also, gender moderates the relationship between bakeries' commitment in frequently evaluating the performance of their contracts with their suppliers, agents or business partners; and the production/output level. However, this relationship exists in bakeries with female owners/managers than bakeries with male owners/managers. The findings also confirm that gender moderates the relationship between bakeries' commitment to frequently test the performance of their product development processes; and the production/output level. This relationship exists in bakeries with male owners/managers than bakeries with female owners/managers. The findings also tell that gender moderates the relationship between bakeries' commitment to frequently test the performance of their operating procedures; and the production/output level. However, this relationship exists in bakeries with female owners/managers than bakeries with male owners/managers. Similarly, gender moderates the relationship between bakeries' commitment in frequently requesting for feedback from customers with regard to their product performance in terms of price, packaging, ingredients, and taste; and the production/output level. This relationship exists in bakeries with male owners/managers than bakeries with female owners/managers. Similarly, based on these relationships, we argue that there are both males' and females' commitments in adopting risk controlling techniques. These commitments influence production/output performance. All the results corroborate with the fact that risk controlling needs to 
consider the nature and characteristics of products, processes, and the working environments. This is due to the fact that poor procedures may cause a lot of operational risks. Other causative agents include incapability in detecting respective threats, and failures of relevant systems (Hemrit \& Ben Arab, 2012). Also, the business performance may be contributed to by the respective product development processes (Udegbe, 2014). The relationship between product performance and customer satisfaction is apparent (Sitanggang, Sinulingga, \& Fachruddin, 2019). Additionally, peculiar and appealing innovations as perceived by customers play a vital role in influencing the relationship between product development and business performance (Udegbe \& Udegbe, 2013). However, the competent workforce is needed in integrating risk controlling practices with the interest of key stakeholders such as customers, business partners, suppliers, creditors, and employees to mention a few. This competency is mainly driven by regular employee training in matters pertaining to risk controlling. Employee training is crucial in managing potential risks (Mohammed, 2014).

Strategic Risk Initiatives and Bakery Performance: The findings tell that the age of the bakery moderates the relationship between bakeries' commitment in frequently analyzing the strengths and weaknesses of their major competitors; and the cost level. It also moderates the relationship between bakeries' commitment in frequently requesting for feedback from employees about their satisfaction level against their working environment; and the cost level. The findings also confirm that the age of the bakery moderates the relationship between bakeries' readiness in incurring any additional cost to meet their customers' demands; and the cost level. Similarly, the bakery age moderates the relationship between bakeries' readiness in incurring any additional cost to comply with the legal requirements; and the cost level. It also moderates the relationship between bakeries' readiness in investing in any risky business that will yield significant returns; and the cost level. All these relationships exist in bakeries with basic age than in bakeries with an advanced age. This tells that the readiness and commitment of younger bakeries to adopt strategic risk initiatives is higher than that of bakeries with an advanced age. Again, we argue that their readiness is likely to be attributed to by growth ambitions of most of the young firms. Ultimately, these commitments reduce their production and operation costs. On the other hand, the findings tell that the gender of the bakery owner/manager moderates the relationship between bakeries' commitment in frequently analyzing the strengths and weaknesses of their major competitors; and the production/output level. This relationship exists in bakeries with male owners/managers than bakeries with female owners/managers. Gender also moderates the relationship between bakeries' commitment in frequently requesting for feedback from employees about their satisfaction level against their working environment; and the production/output level. However, this relationship exists in bakeries with male owners/managers and those with female owners/managers. Similarly, gender moderates the relationship between bakeries' readiness to incur any additional cost to meet their customers' demands; and the production/output level. This relationship exists in bakeries with female owners/managers than bakeries with male owners/managers. Again, gender moderates the relationship between bakeries' readiness to incur any additional cost to comply with the legal requirements; and the production/output level. This relationship exists in bakeries with female owners/managers than bakeries with male owners/managers. The findings also confirm that gender moderates the relationship between bakeries' readiness to invest in any risky business that will yield significant returns; and the production/output level. The findings tell that this relationship exists in bakeries with male owners/managers and those with female owners/managers. Again, based on these relationships, we argue that there are both males' and females' commitments in adopting strategic risk initiatives. These commitments influence production/output performance. All the results corroborate with the fact that strategic risk initiatives should focus on integrating risk management practices with strategic business operations and decisions in order to influence competitive advantage. In this regard, both internal and external environments can be analyzed. For example, by carrying out a competitor analysis, the chances of achieving positive performance increase significantly (Adom, Nyarko, \& Som, 2016). However, all the strategic risk initiatives need the support of favorable working environment. The favorable working environment is a driver of positive employee performance (Nderi \& Kirai, 2017). Motivated employees are likely to influence customer satisfaction. The customer satisfaction is mainly contributed to by the commitment of firms in meeting customer demands and offering quality service (Masrurul, 2019). Effective risk management is linked with the provision of quality service and the readiness of SMEs to adopt strategic initiatives that address operational inefficiency and support business mission. 


\section{Conclusion and Recommendations}

This study has revealed that SMEs need to characterize and employ their risk planning strategies in influencing both the reduction of production and operation costs, and the increase in production/output level. These strategies include bakeries' commitment to ensure that they have the relevant knowledge and technical know-how in foreseeing potential hazards, bakeries' commitment in integrating potential hazards in their day to day operations, bakeries' commitment in making an in-depth analysis before entering into any contract with any supplier or business partner, bakeries' commitment in frequently finding whether there are any changes in their business environment related to pricing, technology, products, policies, and legal requirements, and the bakeries' capabilities in developing and using a backup plan whenever unexpected changes in their business and operating environment occur. Both the age of the bakery and gender of the bakery owners/managers moderate the relationship between these strategies; and the cost level, and production/output level respectively. This study has also revealed that SMEs need to characterize and employ their risk controlling strategies in influencing both the reduction of production and operation costs, and the increase in production/output level. These strategies include bakeries' commitment in replacing their appliances and other equipment with new ones as per technical advice, bakeries' commitment to frequently evaluate the performance of their contracts with their suppliers, agents or business partners, bakeries' commitment to frequently test the performance of their product development processes, bakeries' commitment to frequently test the performance of their operating procedures, and bakeries' commitment to frequently request for feedback from customers with regard to their product performance in terms of price, packaging, ingredients, and taste. Again, both the age of the bakery and gender of the bakery owners/managers moderate the relationship between these strategies; and the cost level, and production/output level respectively. This study has also revealed that SMEs need to characterize and employ their strategic risk initiatives in influencing both the reduction of production and operation costs, and the increase in production/output level. These initiatives include bakeries' commitment to frequently analyze the strengths and weaknesses of their major competitors, bakeries' commitment to frequently request for feedback from employees about their satisfaction level against their working environment, bakeries' readiness to incur any additional cost to meet their customers' demands, bakeries' readiness to incur any additional cost to comply with the legal requirements, and bakeries' readiness to invest in any risky business that will yield significant returns. Similarly, both the age of the bakery and gender of the bakery owners/managers moderate the relationship between these strategies; and the cost level, and production/output level respectively. This study recommends that bakeries with an advanced age can adopt the risk planning, risk controlling, and strategic risk initiatives from young bakeries in order to manage their production and operation costs. Nevertheless, both female and male owners/managers need to learn from one another in order to adopt risk planning, risk controlling, and strategic risk initiatives that can increase the production/output performance of their bakeries.

All the results corroborate with the fact that SMEs need to enhance their capabilities in managing risks. One of the enhancement strategies is frequently training their people so as to make them define hazards and their underlying causes, and in predicting their occurrence, and relevant controlling techniques. Without such trainings, there will be internal inefficiencies (Kagwathi, Kamau, Njau, \& Kamau, 2014). The study recommends for the need to have frequent risk management trainings to SME workforce so that they can enhance their competencies in risk planning, risk controlling, and strategic risk initiatives, and eventually link them with their business operations. Through such competences, effective human resource management is enhanced and subsequently increases the survival of SMEs (Mulolli, Islami, \& Skenderi, 2015). Additionally, the involvement of all employees in decision making processes pertaining to enhanced risk management practices should be prioritized by SME owners/managers. SMEs also need to analyze and integrate the role of gender in risk planning, risk controlling, and strategic risk initiatives in order to influence their competitiveness. Nevertheless, the competitiveness of SMEs can be driven by efficient risk management practices in favorable working environments. This study argues that the working environments in SMEs should support the risk management practices. Effective risk management practices can be promoted by the commitment of SMEs to create learning environments that embrace the sharing of risk management knowledge amongst employees. Effective knowledge management practices and information systems need to be adopted by SMEs in order to enhance their risk planning, risk controlling, and strategic risk initiatives. In this regard, the study recommends that the adoption of enterprise risk management in order to facilitate the 
risk management processes in SMEs. The adoption of effective risk management instruments and the enhancement of risk management processes and systems in SMEs need the support of relevant stakeholders. One of the SMEs' key stakeholders in risk management particularly in matters pertaining to capacity building is the government. This study argues that the government support in building SME capability should be sought in order to drive the growth and competitiveness of SMEs (Osei, Forkuoh, Shao, \& Osei, 2016). For example, the capacity building programmes may focus on enabling SMEs to address most of their major business challenges such as poor access to loans particularly big loans that are mainly driven by lack of collaterals, lack of financial management skills, lack of financial discipline, and poor record management skills and systems (Richard \& Mori, 2012). Apart from the government, SMEs need to forge strategic partnerships with key risk management players such as the training institutions, policy development organs, and the financial institutions in order to get a deeper understanding on how to develop and implement effective risk planning, risk controlling, and strategic risk initiatives.

Limitations and Further Studies: The respondents of this study were the owners/managers of the bakeries since they are the top decision makers and chief spokespersons of their SMEs. We argue that the owners/managers cannot understand each and specific details regarding the involvement of their employees in risk management practices. Therefore, specific information and detailed practices especially from the employees who are greatly involved in the development and implementation of risk management strategies would broaden the understanding of the contribution of risk management on SME performance. We also propose that similar studies may be conducted in different industries and in both developed and developing countries, and involve different respondents such as employees, customers, suppliers, agents, rivals, lenders, and relevant business partners.

Acknowledgement: This research was registered and permitted (2018-530-NA-2016-336) by the Tanzania Commission for Science and Technology (COSTECH). It also received an ethical clearance (HSS/1921/018D) from the University of KwaZulu-Natal (UKZN). Both COSTECH and UKZN are highly appreciated. I also appreciate the support given by bakery owners/managers during data collection.

\section{References}

Adom, A. Y., Nyarko, I. K., \& Som, G. N. (2016). Competitor Analysis in Strategic Management: Is it a Worthwhile Managerial Practice in Contemporary Times? Journal of Resources Development and Management, 24, 116-127.

Agburu, J. I., Anza, N. C., \& Iyortsuun, A. S. (2017). Effect of Outsourcing Strategies on the Performance of Small and Medium Scale Enterprises (SMEs). Journal of Global Entrepreneurship Research, 7 (1), 1-34.

Agrawal, R. (2016). 'Enterprise Risk Management' Essential for Survival and Sustainable Development of Micro, Small and Medium Enterprises. International Review (1-2), 117-124.

Aguwa, E. N., \& Arinze-Onyia, S. U. (2014). Assessment of Baking Industries in a Developing Country: The Common Hazards, Health Challenges, Control Measures and Association to Asthma. International Research Journal of Medical Sciences, 2 (7), 1-5.

Alexopoulos, E. C., Kavadi, Z., Bakoyannis, G., \& Papantonopoulos, S. (2009). Subjective Risk Assessment and Perception in the Greek and English Bakery Industries. Journal of Environmental and Public Health, 2009, 1-8.

Almeida, F. (2018). Strategies to Perform a Mixed Methods Study. European Journal of Education Studies, 5 (1), 137-151.

Amin, M. (2015). The Effect of Entrepreneurship Orientation and Learning Orientation on SMEs' Performance: An SEM-PLS Approach. Journal for International Business and Entrepreneurship Development, 8 (3), 215-230.

Ariyanti, F. D., \& Andika, A. (2016). Supply Chain Risk Management in the Indonesian Flavor Industry: Case Study from a Multinational Flavor Company in Indonesia. Proceedings of the 2016 International Conference on Industrial Engineering and Operations Management, (pp. 1448-1455). Kuala Lumpur.

Bakar, L. A., \& Zainol, F. A. (2015). Vision, Innovation, Pro-activeness, Risk-taking and SMEs Performance: A Proposed Hypothetical Relationship in Nigeria. International Journal of Academic Research in Economics and Management Sciences, 4 (1), 45-53.

Basel Committee on Banking Supervision. (2005). International Convergence of Capital Measurement and 
Capital Standards: A Revised Framework. Basel: Bank for International Settlements.

Basile, A. (2012). Entrepreneurial Orientation in SMEs: Risk-taking to Entering International Markets. Far East Journal of Psychology and Business, 7 (2), 1-17.

Belinskaja, L., \& Velickiene, M. (2015). Business Risk Management: Features and Problems in Small and Medium-Sized Trading and Manufacturing Enterprises. European Scientific Journal, 2 (June Special Edition), 30-58.

Bengesi, K. M., \& Le Roux, I. (2014). The Influence of Dimensions of Networking Capability in Small and Medium Enterprise Performance. International Journal of Business and Social Science, 5 (2), 189-200.

Bennett, B., Naziri, D., Mahende, G., \& Towo, E. (2012). Driving Demand for Cassava in Tanzania: The Next Steps. Natural Recourse Institute, University of Greenwich.

Brodowska, M., Guzek, D., \& Wierzbicka, A. (2014). Modern Technological Solutions Used in the Production of Bakery Products with High Biological Value. Advances in Science and Technology Research Journal , 8 (22), 83-92.

Brustbauer, J. (2016). Enterprise Risk Management in SMEs: Towards a Structural Model. International Small Business Journal , 34 (1), 70-85.

Cantaleano, K. R., Rodrigues, G. P., \& Martins, T. S. (2018). The Mediating Effect of Proactive Market Orientation Capability in Entrepreneurial Orientation and Service Innovation. Revista de Administração Mackenzie, 19 (1), 1-27.

Chauvet, G. (2015). Coupling Methods for Multistage Sampling. The Annals of Statistics, 43 (6), 2484-2506.

Chongela, J. (2015). Contribution of Agriculture Sector to the Tanzanian Economy. American Journal of Research Communication, 3 (7), 57-70.

COSO. (2004). Enterprise Risk Management-Integrated Framework. Committee of Sponsoring Organizations of the Treadway Commission.

Crovini, C. (2017). New Perspectives in Managing Risks in SMEs. 10th Annual Conference of the EuroMed Academy of Business (pp. 496-509). Roma: EuroMed Press.

Das, T. K., \& Teng, B. (2000). A Resource-Based Theory of Strategic Alliances. Journal of Management, 26 (1), 31-61.

DeVellis, R. F. (2003). Scale Development: Theory and Applications (2nd ed.). Thousand Oaks: Sage Publications.

Dominguez, N., \& Raïs, M. (2012). Risk-seeking Behaviours in Growth Strategies of SMEs: Targeting Unstable Environments. 15th McGill International Entrepreneurship Conference. Pavia: McGill International Entrepreneurship (MIE) Conference Series, McGill University.

Fadun, O. S. (2013). Risk Management and Risk Management Failure: Lessons for Business Enterprises. International Journal of Academic Research in Business and Social Sciences, 3 (2), 225-239.

Fairoz, F. M., Hirobumi, T., \& Tanaka, Y. (2010). Entrepreneurial Orientation and Business Performance of Small and Medium Scale Enterprises of Hambantota District Sri Lanka. Asian Social Science, 6 (3), 3446.

Falkner, E. M., \& Hiebl, M. R. (2015). Risk Management in SMEs: A Systematic Review of Available Evidence. The Journal of Risk Finance, 16 (2), 122-144.

Fejza, E., Ismajli, A., \& Misini, S. (2013). Competitive Analyses of Local Bakeries in Prishtina/Republic of Kosovo. 1st Annual International Interdisciplinary Conference, AIIC, (pp. 50-55). Azores.

Fjose, S., Grünfeld, L. A., \& Green, C. (2010). SMEs and Growth in Sub-Saharan Africa:Identifying SME Roles and Obstacles to SME Growth. Oslo: MENON Business Economics.

Geyskens, I., Steenkamp, J.-B. E., \& Kumar, N. (2006). Make, Buy, or Ally: A Transaction Cost Theory MetaAnalysis. Academy of Management Journal, 49 (3), 519-543.

Gorzeń-Mitka, I. (2015). Risk Management in Small and Medium-Sized Enterprises: A Gender-Sensitive Approach. Problems of Management in the 21st Century, 10 (2), 77-87.

Hamisi, S. (2011). Challenges and Opportunities of Tanzanian SMEs in Adapting Supply Chain Management. African Journal of Business Management, 5 (4), 1266-1276.

Harner, M. M. (2010). Barriers to Effective Risk Management. Seton Hall Law Review, 40 (4), 1323-1365.

Hemrit, W., \& Ben Arab, M. (2012). The Major Sources of Operational Risk and the Potential Benefits of its Management. Journal of Operational Risk, 7 (4), 71-92.

Irawanto, D. W. (2015). Employee Participation in Decision-making: Evidence from a State-owned Enterprise in Indonesia. Management - Journal of Contemporary Management Issues, 20 (1), 159-172.

Jenya, B., \& Sandada, M. (2017). Enhancing Success of SMEs through Risk Enterprise Management: 
Evidence from a Developing Country. Pakistan Journal of Applied Economics, 27 (2), 173-188.

Kagwathi, G. S., Kamau, J. N., Njau, M. M., \& Kamau, S. M. (2014). Risks Faced and Mitigation Strategies Employed by Small and Medium Enterprises in Nairobi, Kenya. IOSR Journal of Business and Management, $16(4), 1-11$.

Kapaya, S. M., Shayo, F. A., Jaensson, J.-E., \& Stanslaus, V. (2018). The Role of Entrepreneurial Orientation on Business Performance: Empirical Evidence from Selected Tanzanian SME's. The Pan-African Journal of Business Management, 2 (1), 15-34.

Katua, N. T. (2014). The Role of SMEs in Employment Creation and Economic Growth in Selected Countries. International Journal of Education and Research, 2 (12), 461-472.

Katunzi, T. M., \& Zheng, Q. (2010). Tanzanian SMEs' Perceptions towards Adoption of Supply Chain Management (SCM) Strategy. International Journal of Business and Management, 5 (10), 42-50.

Kazimoto, P. (2014). Assessment of Challenges facing Small and Medium Enterprises towards International Marketing Standards: A Case Study of Arusha Region Tanzania. International Journal of Academic Research in Accounting, Finance and Management Sciences, 4 (2), 303-311.

Kehinde, A., Opeyemi, A., Benjamin, A., Adedayo, O., \& Abel, O. A. (2017). Enterprise Risk Management and the Survival of Small Scale Businesses in Nigeria. International Journal of Accounting Research, 5 (2), 1-8.

Kiprotich, S., Kimosop, J., Kemboi, A., \& Chepkwony, P. K. (2015). Moderating Effect of Social Networking on the Relationship between Entrepreneurial Orientation and Performance of Small and Medium Enterprise in Nakuru County, Kenya. European Journal of Small Business and Entrepreneurship Research, 3 (2), 38-52.

Kitigin, B. (2017). Relationship between Risk-taking and Business Performance among Small and Medium Enterprises in Eldoret Town, Kenya. International Journal of Business and Management Review, 5 (7), 52-59.

Kline, R. B. (2005). Principles and Practice of Structural Equation Modelling (2nd ed.). New York: Guilford Publications.

Krejcie, R. V., \& Morgan, D. W. (1970). Determining Sample Size for Research Activities. Educational and Psychological Measurement, 30, 607-610.

Lawal, F. A., Adegbuyi, O. A., Iyiola, O. O., Ayoade, O. E., \& Taiwo, A. A. (2018). Nexus between Informal Networks and Risk-taking: Implications for Improving the Performance of Small and Medium Enterprises (SMEs) in Nigeria. Academy of Strategic Management Journal, 17 (2), 1-13.

Lee, I. H., \& Marvel, M. R. (2009). The Moderating Effects of Home Region Orientation on R\&D Investment and International SME Performance: Lessons from Korea. European Management Journal, 27 (5), 316326.

Leiblein, M. J. (2003). The Choice of Organizational Governance Form and Performance: Predictions from Transaction Cost, Resource-based, and Real Options Theories. Journal of Management, 29 (6), 937961.

Lopez-Perez, M. V., Perez-Lopez, M. C., \& Rodriguez-Ariza, L. (2013). Ownership Governance and Performance in Spanish-Moroccan Joint Ventures. South African Journal of Economic and Management Sciences, 16 (3), 231-243.

Louw, A., Troskie, G., \& Geyser, M. (2013). Small Millers' and Bakers' Perceptions of the Limitations of Agro-processing Development in the Wheat-milling and Baking Industries in Rural Areas in South Africa. Agrekon, 52 (3), 101-122.

Lukianchuk, G. (2015). The Impact of Enterprise Risk Management on Firm Performance of Small and Medium Enterprises. European Scientific Journal, 11 (13), 408-427.

Maladzhi, W. R. (2015). Impact of Risk-Taking Leadership on Organisational Performance and Sustainability in SMEs. 2015 IEEE International Conference on Industrial Engineering and Engineering Management (IEEM) (pp. 1752-1756). Singapore: IEEE.

Maliti, E., \& Mnenwa, R. (2008). The Role of Small Businesses in Poverty Alleviation: The Case of Dar es Salaam, Tanzania. Dar es Salaam: Research on Poverty Alleviation (REPOA).

Marques, N. R., Matias, J. C., Teixeira, R. R., \& Brojo, F. M. (2012). Implementation of Hazard Analysis Critical Control Points (HACCP) in a SME: Case Study of a Bakery. Polish Journal of Food and Nutrition Sciences, 62 (4), 215-227.

Mashenene, R. G., \& Rumanyika, J. (2014). Business Constraints and Potential Growth of Small and 
Medium Enterprises in Tanzania: A Review. European Journal of Business and Management, 6 (32), 72-79.

Mason, M. C., Floreani, J., Miani, S., Beltrame, F., \& Cappelletto, R. (2015). Understanding the Impact of Entrepreneurial Orientation on SMEs' Performance. The Role of the Financing Structure. Procedia Economics and Finance, 23, 1649-1661.

Masrurul, M. M. (2019). Impact of Service Quality on Customer Satisfaction in Bangladesh Tourism Industry: An Empirical Study. Advances In Management, 12 (1), 79-83.

Mithwani, A. M. (2015). Factors Influencing Strategy Implementation in the Bakery Industry in Mombasa County. The International Journal of Business \& Management, 3 (8), 185-200.

Mohammed, K. M. (2014). Training to Manage Risk: Focusing on the Essential. Journal of Advanced Management Science, 2 (1), 1-6.

Mori, G. T., Kazungu, I., \& Mchopa, A. (2014). Strategic Planning: A Management Contrivance for Effective Performance of Small and Medium Enterprises in Tanzania? A Survey of Selected SMEs in Ilala Municipality. European Journal of Business and Management, 6 (39), 193-203.

Mulolli, E., Islami, X., \& Skenderi, N. (2015). Human Resource Management Practices and SMEs Performance: Study Based in Kosovo. International Review of Management and Business Research, 4 (4), 1171-1179.

Naldi, L., Nordqvist, M., Sjöberg, K., \& Wiklund, J. (2007). Entrepreneurial Orientation, Risk Taking, and Performance in Family Firms. Family Business Review, 20 (1), 33-47.

Nanthuru, S. B., Pingfeng, L., Guihua, N., \& Mkonya, V. L. (2018). An Assessment of Risk Management Practices of SME Taxpayers in Malawi and their Impact on Tax Compliance. International Journal of Management Science and Business Administration, 4 (4), 7-17.

Nderi, F. W., \& Kirai, M. (2017). Influence of Work Environment on Employee Performance in the Security Sector in Kenya: A Case of Kenya Police Service Nairobi City County. The Strategic Journal of Business \& Change Management, 4 (4), 1010-1036.

Nikolaeva, E., \& Pletnev, D. (2016). The Role of the Transaction Costs in the Business Success of Small and Medium Sized Enterprises in Russia. Procedia - Social and Behavioral Sciences, 221, 176-184.

Nocco, B. W., \& Stulz, R. M. (2006). Enterprise Risk Management: Theory and Practice. Journal of Applied Corporate Finance, 18 (4), 8-20.

Nyangarika, A. (2016). Impact of Networking on Performance of Small and Medium Enterprises in Tanzania. European Journal of Business and Management, 8 (6), 48-57.

Oleiniuc, M. (2012). Strategic Controlling Implementation in Moldovan Bakery Industry. Annals - Economy Series, 1, 117-120.

Osei, A., Forkuoh, K. S., Shao, Y., \& Osei, M. A. (2016). The Impact of Institutional Support in SMEs Marketing, and Growth-A Case Study of Retail SMEs in Ghana. Open Journal of Business and Management, 4 (3), 408-426.

Pervan, M., Pervan, I., \& Ćurak, M. (2017). The Influence of Age on Firm Performance: Evidence from the Croatian Food Industry. Journal of Eastern Europe Research in Business and Economics, 2017, 1-10.

Priyanath, H. M., \& Premaratne, S. P. (2018). Effect of Social Capital on Mitigating Transaction Uncertainty of Small Enterprises in Sri Lanka. Journal of Business and Economic Development, 3 (1), 1-10.

Pundir, R. K., \& Jain, P. (2011). Qualitative and Quantitative Analysis of Microflora of Indian Bakery Products. Journal of Agricultural Technology, 7 (3), 751-762.

Quaye, W., Onumah, J. A., Tortoe, C., Akonor, P. T., \& Buckman, E. (2018). Investigating the Adoption of the Root and Tuber Composite Flour (RTCF) Technology Transferred among Micro- and Small-scale Entrepreneurs (MSEs) in the Bakery Industry in Ghana. African Journal of Science, Technology, Innovation and Development, 10 (2), 137-145.

Rasheli, G. A. (2016). Small Business Value Chains in Local Government Authorities (LGAs) Procurement Contracts in Tanzania. Cogent Business \& Management, 3 (1), 1-11.

Richard, E. M., \& Mori, N. G. (2012). SMEs Access to Financial Services: Bankers' Eye. Chinese Business Review, 11 (2), 217-223.

Riordan, M. H., \& Williamson, O. E. (1985). Asset Specificity and Economic Organization. International Journal of Industrial Organization, 3, 365-378.

Robu, M. (2013). The Dynamic and Importance of SMEs in Economy. The USV Annals of Economics and Public Administration, 13 (1(17)), 84-89.

Rocha, F. B., Oliveira, L. F., Campos, M. C., Oliveira, L. P., \& Saldanha, M. C. (2009). Analysis of Ergonomic 
Demands in the Bread Making Section of a Bakery in Natal/RN: A Case Study. XV International Conference on Industrial Engineering and Operations Management. Salvador: http://www.abepro.org.br/biblioteca/enegep2009_TI_ST_094_639_13738.pdf.

Rosenbusch, N., Brinckmann, J., \& Bausch, A. (2011). Is Innovation Always Beneficial?A Meta-Analysis of the Relationship between Innovation and Performance in SMEs. Journal of Business Venturing, 26 (4), 441-457.

Rosli, M. M., \& Sidek, S. (2013). The Impact of Innovation on the Performance of Small and Medium Manufacturing Enterprises: Evidence from Malaysia. Journal of Innovation Management in Small \& Medium Enterprise, 2013.

Salojärvi, S., Furu, P., \& Sveiby, K.-E. (2005). Knowledge Management and Growth in Finnish SMEs. Journal of Knowledge Management, 9 (2), 103-122.

Santos, J. L., Erdmann, A. L., Meirelles, B. H., Lanzoni, G. M., Cunha, V. P., \& Ross, R. (2017). Integrating Quantitative and Qualitative Data in Mixed Methods Research. Texto \& Contexto Enfermagem, 26 (3), $1-9$.

Savlovschi, L. I., \& Robu, N. R. (2011). The Role of SMEs in Modern Economy. Economia. Seria Management, 14 (1), 277-281.

Shahzad, K. (2017). From Transaction Cost Containment to Relationship Commitment: An Integrative Perspective of Buyer-Supplier Relationship Governance. Management International Conference (pp. 211-221). Monastier di Treviso: University of Primorska Press.

Sitanggang, J. M., Sinulingga, S., \& Fachruddin, K. A. (2019). Analysis of the Effect of Product Quality on Customer Satisfaction and Customer Loyalty of Indihome ATPT Telkom Regional 1 Sumatera, Medan, North Sumatra, Indonesia. American International Journal of Business Management, 2 (3), 26-37.

Smit, Y., \& Watkins, J. A. (2012). A Literature Review of Small and Medium Enterprises (SME) Risk Management Practices in South Africa. African Journal of Business Management, 6 (21), 6324-6330.

Smith, J. P., Daifas, D. P., El-Khoury, W., Koukoutsis, J., \& El-Khoury, A. (2004). Shelf Life and Safety Concerns of Bakery Products-A Review. Critical Reviews in Food Science and Nutrition, 44 (1), 19-55.

Soltanizadeh, S., Rasid, S. Z., Golshan, N., Quoquab, F., \& Basiruddin, R. (2014). Enterprise Risk Management Practices among Malaysian Firms. Procedia - Social and Behavioral Sciences, 164, 332337.

Sprčić, D. M., Kožul, A., \& Pecina, E. (2015). State and Perspectives of Enterprise Risk Management System Development - The Case of Croatian Companies. Procedia Economics and Finance, 30, 768-779.

Sum, R. M., \& Mahussin, N. (2017). Risk Management Practices of a Small Enterprise: A Case Study on a Bakery Shop. Proceedings of 4th International Muamalat and Entrepreneurship Conference (IMEC4). Nilai: Islamic Finance and Wealth Management Institute (IFWMI), The 13th Islamic Convention Entrepreneurship (ICEPS13), and Malaysian Muamalat Association (MMA).

Udegbe, S. E. (2014). New Product Development Process and its Impact on Business Performance in Nigeria. The Business \& Management Review, 4 (4), 25-39.

Udegbe, S. E., \& Udegbe, M. I. (2013). Impact of Product Development and Innovation on Organisational Performance. International Journal of Management and Sustainability, 2 (12), 220-230.

URT \& UNIDO. (2012). Tanzania Industrial Competitiveness Report 2012. Ministry of Industry and Trade of the United Republic of Tanzania (MIT), President's Office Planning Commission of the United Republic of Tanzania (POPC) and United Nations Industrial Development Organization (UNIDO).

Valdez-Juárez, L. E., García-Pérez de Lema, D., \& Maldonado-Guzmán, G. (2016). Management of Knowledge, Innovation and Performance in SMEs. Interdisciplinary Journal of Information, Knowledge, and Management, 11, 141-176.

Van Der Spiegel, M., Luning, P. A., De Boer, W. J., Ziggers, G. W., \& Jongen, W. M. (2005). How to Improve Food Quality Management in the Bakery Sector. NJAS - Wageningen Journal of Life Sciences, 53 (2), 131-150.

Verbano, C., \& Venturini, K. (2013). Managing Risks in SMEs: A Literature Review and Research Agenda. Journal of Technology Management \& Innovation, 8 (3), 186-197.

Voulgaris, F., Asteriou, D., \& Agiomirgianakis, G. (2003). The Determinants of Small Firm Growth in the Greek Manufacturing Sector. Journal of Economic Integration, 18 (4), 817-836.

Wambugu, A. W., Gichira, R., Wanjau, K. N., \& Mung'atu, J. (2015). The Relationship between Risk Taking and Performance of Small and Medium Agro Processing Enterprises in Kenya. International Journal of Economics, Commerce and Management, 3 (12), 441-455. 
Williamson, O. E. (1973). Markets and Hierarchies: Some Elementary Considerations. The American Economic Review, 63 (2), 316-325.

Williamson, O. E. (1999). Public and Private Bureaucracies: A Transaction Cost Economics Perspective. The Journal of Law, Economics, \& Organization, 15 (1), 306-342.

Williamson, O. E. (1981). The Economics of Organization:The Transaction Cost Approach. The American Journal of Sociology, 87 (3), 548-577.

Williamson, O. E. (1997). Transaction Cost Economics and Public Administration. In P. B. Boorsma, K. Aarts, \& A. E. Steenge, Public Priority Setting: Rules and Costs (pp. 19-37). Netherlands: Springer Netherlands.

Williamson, O. E. (1979). Transaction-Cost Economics:The Governance of Contractual Relations. Journal of Law and Economics, 22 (2), 233-261.

Wimba, I. G., Budhi, I. M., Yasa, I. G., \& Saskara, I. A. (2015). Effect of Social Capital on Entrepreneurial Orientation and Transaction Cost to Improve Firm Performance in Wooden Craft SMEs in Bali Province-Indonesia. International Journal of Economics, Commerce and Management, 3 (10), 240-256.

Wu, P., Yao, X., \& Muhammad, S. (2017). The Effect of Female Participation in Top Management Teams on the Growth Performance of Small and Medium-sized Enterprises (SMEs): Evidence from a Panel-data Analysis in Chinese-listed SMEs. Asia Pacific Journal of Innovation and Entrepreneurship, 11 (1), 108119.

Yang, S., Ishtiaq, M., \& Anwar, M. (2018). Enterprise Risk Management Practices and Firm Performance, the Mediating Role of Competitive Advantage and the Moderating Role of Financial Literacy. Journal of Risk and Financial Management, 11 (3), 1-17.

Zhai, Y.-M., Sun, W.-Q., Tsai, S.-B., Wang, Z., Zhao, Y., \& Chen, Q. (2018). An Empirical Study on Entrepreneurial Orientation, Absorptive Capacity, and SMEs' Innovation Performance: A Sustainable Perspective. Sustainability, 10 (2), 314.

Zoghi, F. S. (2017). Risk Management Practices and SMEs: An Empirical Study on Turkish SMEs. International Journal of Trade, Economics and Finance, 8 (2), 123-127.

Zou, X., \& Hassan, C. H. (2015). Practicality and Potential Value of Enterprise Risk Management in the Manufacturing Sector in China. Pertanika Journal of Social Science and Humanities, 23 (Special Issue), $1-12$. 